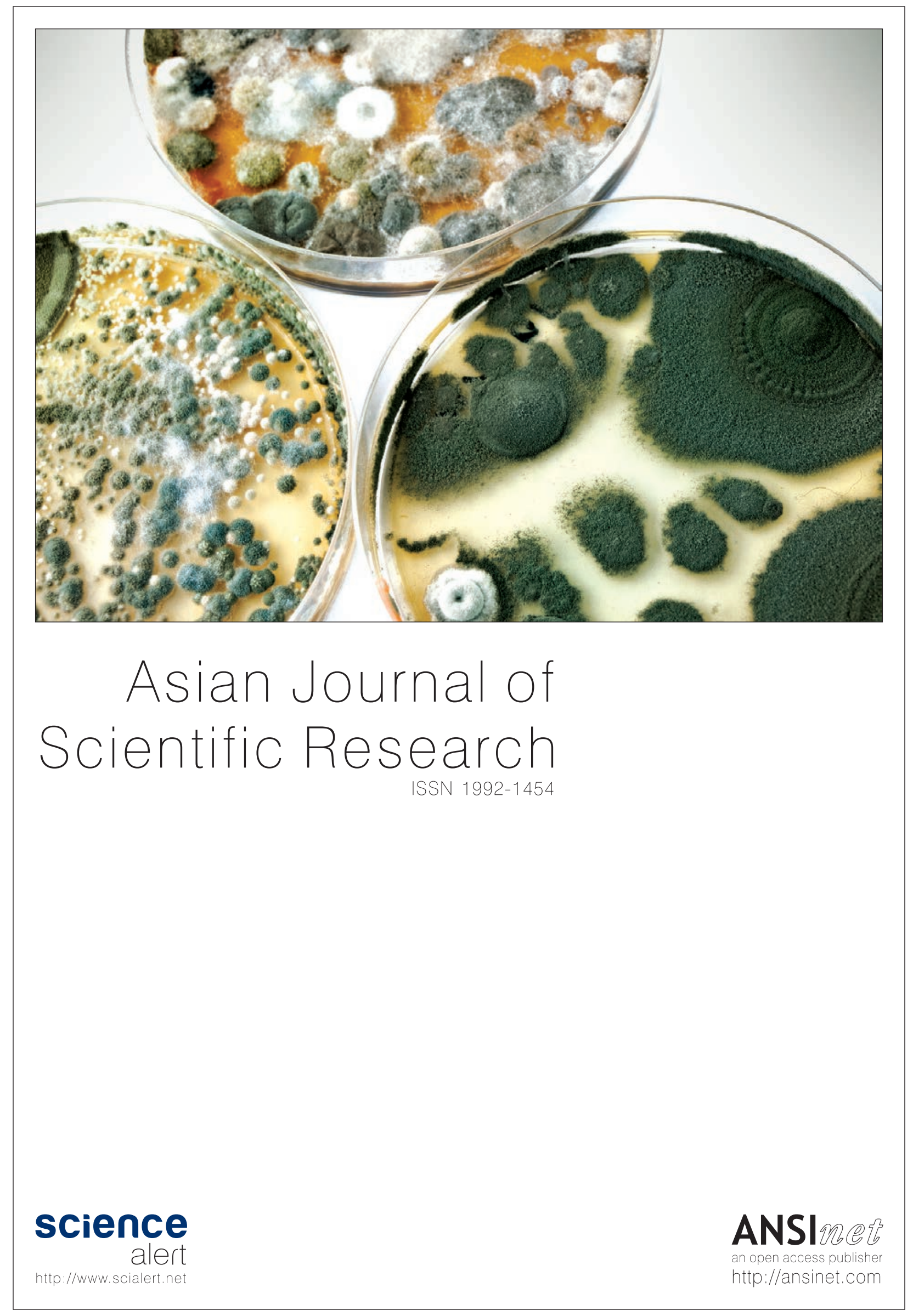




\title{
Research Article \\ Designing Training Module to Improve Nursing Clinical Competence Based on Needs Analysis: A Developmental Study
}

\author{
${ }^{1}$ Tiarnida Nababan and ${ }^{2}$ Erikson Saragih \\ ${ }^{1}$ Department of Nursing, Faculty of Nursing and Midwifery, Universitas Prima Indonesia, Medan, Indonesia \\ ${ }^{2}$ Department of English, Faculty of Teaching Training and Education, Universitas Prima Indonesia, Medan, Indonesia
}

\section{Abstract}

Background and Objective: Competence refers to knowledge, skills, abilities and traits. It is gained in the health care professions through pre-service education, in-service training and study experience. Based on some nursing education institution reports, few nursing graduates are competent and ready for professional work. Measuring competence is essential to determine the ability and readiness of health workers to provide quality services. In order to improve nursing competence, there have been some efforts made by nursing education institutions in Indonesia. The research objectives were, firstly to explore needs analysis of nursing clinical competency at hospitals in Indonesia and overseas, secondly to design training module for improving nursing clinical competence based on the results of needs analysis. Methodology: This research applied developmental research method, planning, conducting and reporting the results. The research data were the result of in depth-interview with 3 senior nurse managers of 3 hospitals, FGD with nursing students and nursing clinical competency assessors concerning required nursing clinical competencies and the results of the needs analysis were taken as a basis for constructing a training module for improving quality of nursing clinical competence applying developmental research design. Results: The results of FGD revealed that 8 nursing competency domains need to be well comprehended by nursing graduates covering 32 major clinical competencies. From the needs analysis, a training module for improving nursing clinical competency was arranged and developed to meet requirements as stated in needs analysis. The designed module has proved to be effective in improving clinical competency of nursing graduates as observed in simulation assessment model. Conclusion: Based on the results, it is concluded that nursing clinical competence can be improved by using needs analysis and well designed training module that directly touches the required nursing clinical competence in practice.

Key words: Nursing clinical competence, module, needs analysis, developmental research, nursing education

$\begin{array}{lll}\text { Received: September 19, } 2017 & \text { Accepted: December 11, } 2017 & \text { Published: June 15, } 2018\end{array}$

Citation: Tiarnida Nababan and Erikson Saragih, 2018. Designing training module to improve nursing clinical competence based on needs analysis: a developmental study. Asian J. Sci. Res., 11: 319-328.

Corresponding Author: Erikson Saragih, Department of English, Faculty of Teaching Training and Education, Universitas Prima Indonesia, Jalan Danau Singkarak/Madrasah No.1, Sei Agul, Medan, Sumatera Utara, Post code 20117, Indonesia Tel: +6261-4532820/08126325193

Copyright: @ 2018 Tiarnida Nababan and Erikson Saragih. This is an open access article distributed under the terms of the creative commons attribution License, which permits unrestricted use, distribution and reproduction in any medium, provided the original author and source are credited.

Competing Interest: The authors have declared that no competing interest exists.

Data Availability: All relevant data are within the paper and its supporting information files. 


\section{INTRODUCTION}

For years, the term "competence" remains a complex concept that is difficult to define and even more difficult to measure ${ }^{1}$. This presents particular problems for the nursing profession as patient outcomes may be compromised by poor practice. While universities aim to prepare nurses to work in complex, dynamic and unpredictable clinical environments, however, clinical assessments are focused on psychomotor skills and fail to take into account the multi-dimensional nature of competence and the range of attributes required for professional practice ${ }^{2}$. In order to address these educational and professional concerns, the institution of nursing education should have a training module of clinical competence for the bachelor of nursing program at the authors' university. This paper outlines needs analysis of nursing competence and design a module for nursing competence. It is a comprehensive and practice-driven clinical practice that motivates student learning, promotes critical reaction and confirms graduates' readiness for professional practice.

Recently, rapid progress of health science and the demands for quality health services, especially nursing keep increasing significantly. This condition reinforces nursing education institutions to prepare their graduates to have good clinical competencies for their readiness for professional work. Competence refers to the ability to perform a specific task in a manner that yields desirable outcomes. Indonesian Competency Standards for the Registered ' $r \mathrm{se}^{3}$ defines that competency refers to the combination of skills, knowledge, attitudes, values and abilities that underpin effective and/or superior performance in a profession/occupational area. This definition implies the ability to apply knowledge, skills and abilities successfully to new situations as well as to familiar tasks for which prescribed standards exist. The above nursing care is provided by a nurse who has the ability to adapt, act intelligently, responsibly and competitively to the demands of change. Such capability can be possessed by nurses through education both formally and non-formally as an effort to achieve and keep their competencies "up to date".

A proper definition of clinical competence and its components is important to serve as a criterion for validating medical educational programs and to assure a minimum level of competency at the end of nursing school and beyond during residency. Understanding clinical competence is crucial not only for nursing education, assessment and licensing examinations but also for society and its responsibility for the quality of health care. Many clinical educators, committees, specialty boards and expert panels within and outside the nursing profession have noticed the importance of defining what is required of a health care professional and have spent time and effort in attempting to describe clinical competence. Some researchers suggested that competence be conceptualized as effective interaction with the environment. This means that clinical competence manifests itself only in observed behaviors or practice. A description of competence according to the tasks of the clinical encounter, such as history taking, physical examination, use of laboratory tests, patient management, record keeping, etc. was helpful to get insights on the purpose and consequence of physicians' behaviors.

A clear and concise definition of clinical competence seems most pressing for assessment purposes. Miller ${ }^{4}$ distinguished several hierarchical layers of competence to function as a framework for within which assessment might occur (Fig. 1). The different layers in Miller's model represent a developmental sequence of stages, in other words, a horizontally layered hierarchical categorization of clinical competence. All levels are needed and have their own important impact on clinical competence. In his framework for clinical competence a distinction is made between knows (knowledge), knows how (competence), shows how (performance) and does (action). Knowledge is at the base of this triangle shaped framework and action is at the top. A student, resident or physician needs the knowledge that is required to carry out professional functions effectively, a prerequisite for being clinical competent. The next two layers, competence and performance, which follow upon knowledge are often used interchangeably, however, competence means that a physician can apply his/her knowledge in concrete situations, while performance is the ability to use this knowledge to perform concrete actions. The final top layer represents what a physician actually does during day-to-day practice.

Competence is a set of intelligent actions, full of responsibilities possessed by a person as a condition to be considered capable by the community in carrying out certain tasks in the field of study ${ }^{5}$. Indonesian Nursing Competency Standard refers to the Indonesian Nurse Competency Standards issued by the National Nurses Association of Indonesia, through the Decree of the Chairman 024/PP.PPNI/SK/K/XII/2009, on Indonesian Nurses Competency Standards.

Assessing competence of practicing nurses has been identified as crucially important in maintaining professional standard. The best possible uses in patient care are identifying areas of professional development and educational needs and 


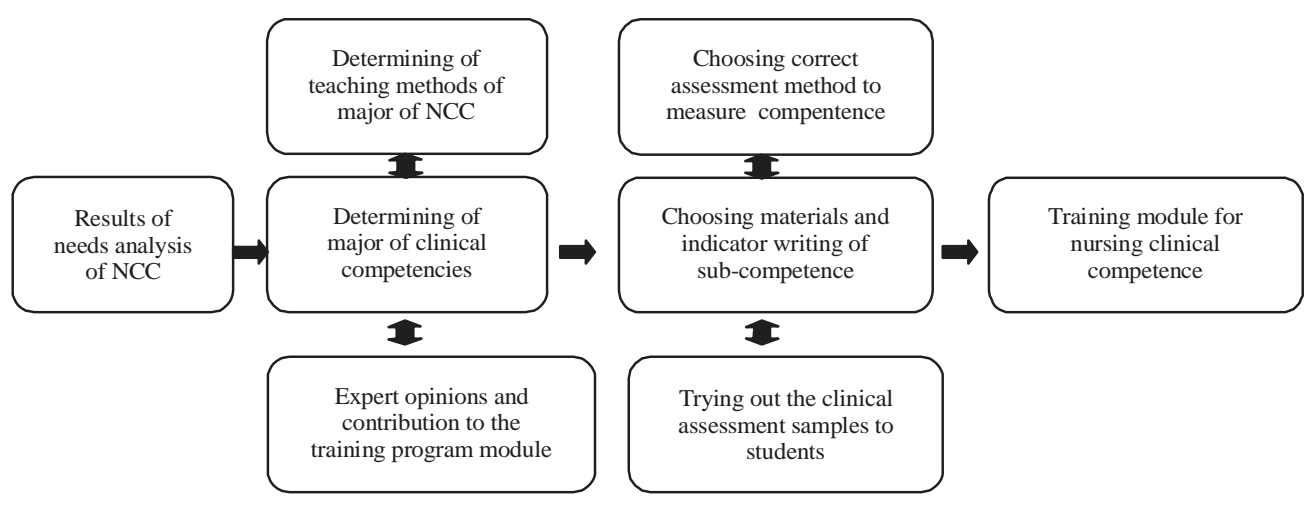

Fig. 1: Steps of designing training module of clinical competence

ensuring nurses have appropriate nursing competencies. Based on the holistic view of competence there is an agreement stating that competence assessment in nursing practice is not only correct demonstration of theoretical content knowledge and technical skills but it must also involve some traits about nurses' attitudes and practices ${ }^{6}$.

One of the challenges underlying clinical assessment is the term 'competence'7 describes three ways of understanding competence: (a) Task related skills, (b) Pertaining to generic attributes essential to effective performance and (c) The bringing together of a range of general attributes such as knowledge, skills and attitudes appropriate for professional practice. This integrated and holistic approach aligns with the definition of competence provided by the Australian Nursing and Midwifery Council Competency Standards for the Registered Nurse defines competence as the combination of skills, knowledge, attitudes, values and abilities that underpin effective and/or superior performance in a profession/occupational area.

There are two additional challenges relating to measuring clinical competence. They are 'reliability' (the extent to which an instrument measures consistently) and 'validity' (the extent to which an instrument measures the construct of interest). Both are fundamental to the assessment of competence. However, Norman et al. ${ }^{8}$ claim that these issues are rarely taken into account in the clinical assessment process. Nurses are assigned to provide quality nursing care and services, in accordance with their areas of expertise and/or authority from various levels of education. Nursing service is a form of professional service which is an integral part of health service for individuals, families, groups and society. Nursing care is a series of activities that are humanistic by using nursing process approach in order to help solve health problems/nursing both actual and potential.
To ensure that each nurse has the required competencies before implementing the nursing service practice, the government of Indonesia has issued the Minister of Health Regulation No. 1796 of 2011 on the registration of health workers. In the ministerial regulation, it is explained that all health workers including nurses must follow the competency test as a condition to obtain registration letter (STR). As Levett-Jones et al. ${ }^{9}$ argues competence test is a process to measure knowledge, skill and attitude according to professional standard in order to give assurance that they are able to perform their profession role safely and effectively in society. To ensure the implementation of quality competence tests, it is necessary to make various preparations such as making module for clinical competence for nurses based on needs analysis and nursing competency standards. The module is the basic framework for nursing students that is the guideline used to take competency test that can ensure that nursing care is provided safely and effectively and describes the main character of the nurse the user expects. This view is in a line with what Lee and $\mathrm{Kim}^{10}$ stated that nurses need to be prepared with a comprehensive module that is able to accommodate all required competencies.

Good competency of health care providers is crucial to high quality of health care. Some researches reveal that the poor performance is mostly caused by low competence. Poor performance of nurses in Indonesia has grasped the government attention recently. The government through LP UKANAKES (an agency to measure competency assessment for health care providers) administers competency assessment for nurse graduates twice in a year. For nurses, the assessment is divided into two levels, for diploma in nursing ( 3 years nursing education) and for nursing profession (5-years nursing education). In the average, most graduates (diploma level and nursing profession) only $55 \%$ of all nursing graduates 
from diploma level who were competent while the rest $45 \%$ were categorized incompetent. For professional nursing graduates, it was noted that $58 \%$ who were competent while $42 \%$ were incompetent ${ }^{11}$.

In broad terms, competency standards recommend expected levels of knowledge, attitudes, skills and behaviors. Completeness for professional nursing should reflect comprehensive nature of nursing practice, the broad range of practice settings and cultural differences within Indonesian population. To overcome obstacles in the lack of graduate competence, nursing education institutions in Indonesia need to establish a training program of nursing clinical competence so that nurses have high competence and quality. This research was conducted to observe the needs analysis of nursing clinical competency to design a training module that can be used by nursing education institutions in Indonesia having problems with their low clinical competency of their graduates. Hopefully, this clinical competency training module really reflects material contents that are urgently needed by nurse graduates that touch directly to their prospective career.

As a rational of this study, there have been a range of indicators and tools being developed for clinical competence assessment for nurses, however, empirical evidence regarding improvement of nursing clinical competence was rarely identified ${ }^{12}$. Regarding of clinical competency assessment, it is essential that there is an adequate training or preparation of individual nurses being trained using a well-arranged and developed training module, therefore, a systematic study of designing, developing and evaluating an instructional program is urgently needed. The training module must meet criteria of internal consistency and effectiveness ${ }^{13}$. This module focuses on preparing learners perform their professional roles in health promotion whether promoting health of individuals or communities. Learners need to learn the health promotion theories, models and strategies that can guide their actions in implementing health promotion programs. Specific skills in planning, implementing and evaluating health promotion are also important to the success of training program and to improve quality of life of the clients. In the specific learning strategies presented in the moudule, case scenarios are used to situate and put context in the performance of the competencies.

This study can contribute to lecturers, training designers of nursing clinical competency at nursing education institutions by designing their own module to improve clinical nursing competence and performance. The study focuses on the investigation of needs analysis of nursing clinical competence from the hospital authority and related priority literature to design the training module. This study is very important to do because the results will provide a clear description of the competence of nurses, nurses competence measurement and training modules nursing clinical competence.

\section{MATERIALS AND METHOD}

The materials of the study are domains of nursing care and competency, how are competencies acquired, factors affecting nursing performance, competency assessment methods and social factors affecting competency. The research applied two research methods, needs analysis and developmental research method. The needs analysis method was used to gather all qualitative data relating to the domains of nursing competency while developmental research method was applied to produce an appropriate training module for improving nursing clinical competence. The instruments used to collect data include observation. The qualitative data were derived from online interview from participants consisting of two nursing managers from accredited hospitals outside Indonesia, two nursing managers from hospitals in Indonesia and 2 senior nursing lecturers from reputable universities in Indonesia. The qualitative data were derived from the participants which were then analyzed to represent needs analysis of nursing competence and performance as guidelines to design a nursing competency nursing module. The needs analysis method used in this study follows steps proposed by McKillip ${ }^{14}$ which consist of identifying the audience and purposes for the analysis, describing the target population and service environment, identifying the needs where descriptions of the problems and generating the possible solutions and evaluating the identified needs. Needs analysis focuses on the future or what should be done rather than on what was done as is the focus of most program evaluations.

Needs analysis: A needs analysis initiates the involvement and engagement of all stakeholders and recognizes that the success of a change programme relies on taking account of peoples' feelings and beliefs. Involving stakeholders in planning and implementation increases the likelihood of commitment and ownership of initiatives.

This needs analysis aims to: 
- Assess the current levels, teaching practices and needs of nursing clinical competency

- Define the baseline situation of teaching and learning of nursing clinical competency

- Identify what is needed and why in order to bridge the gap between the existing situation and the proposed changes

- Ensure that all stakeholders' voices are considered, therefore increasing buy-in and commitment to any potential project

- Enable the development of delivery models and training modules that will be relevant to the needs and requirements of the nurses and socio-cultural contexts

The research team conducted the needs analysis in 5 nursing education institutions in 5 major cities in Indonesia from 24th June and 3th July, 2016. The research team visited the institutions to observe the nursing clinical assessment. They were accompanied and supported by the head of nursing education institutions. This needs analysis report is generated from both primary and secondary data. Primary sources comprised data obtained through clinical assessment observations, focus groups discussions and interviews taking photographs during their interactions with examiners and synthesizing their observations into analytical reports.

Needs analysis tools: The tools were developed by Indonesian Nursing Association (PPNI) and revised by research team for this needs analysis. The research team had been trained on needs analysis procedures. The needs analysis tools had been previously adapted with some appropriate literatures and expert opinions of nursing clinical competence assessors (Table 1).

\section{RESULTS}

\section{Results of focus group $D$}

\section{Question 1: Why measures clinical nursing competence?:}

There are many good reasons for measuring competence. Firstly, The increasing complexities of health care delivery and changing market conditions have forced health policy-makers to promote the assessment of initial competence of students and new graduates and the continuing competence of experienced and certified practitioners. Secondly, comparing assessments of competence and job performance may indicate the extent to which the organization provides the 
support needed for quality care. Thirdly, healthcare organizations are responsible for the quality of care their staff provide and consequently must ensure that their staffs are competent and can meet standards for the provision of care. Assessing providers' competence periodically enables healthcare organizations to meet this crucial responsibility. Fourthly, competency assessments can be used to monitor organization-wide knowledge of policies and procedures related to high-risk areas. Fifthly, competency assessment is an integral part of the certification and recertification processes of service providers.

Question 2: What are major domains of clinical nursing competence?: The FGD administered to the 2 heads of Indonesian Nursing Association decision makers of nursing competence revealed that there are 8 domains of nursing competency that are needed by nurses to comprehend and performed. They are, the helping role, the diagnostic and monitoring function, administering and monitoring therapeutic interventions and effective management of rapidly changing situations. The teaching-coaching function, monitoring and ensuring the quality of healthcare practices, Organizational and work-role competencies. The consulting role.

Competency domains of helping roles include: The healing relationship, providing comfort measures and preserving personhood in the face of pain and/or extreme breakdown, maximizing the patient's participation and control in her/her own recovery, providing informational and emotional support to patient's family and guiding patient through emotional and developmental change, providing new options, closing old ones.

\section{Competency domains of diagnostic and monitoring} functions cover: Detecting and documenting significant changes in patient's condition, providing an early warning signal: Anticipating breakdown and deterioration prior to explicit, confirming diagnostic signs, anticipating problems, understanding the particular demands and experiences of an illness: Anticipating patient care needs and assessing the patient's potential for wellness and for responding to various treatment strategies.

\section{Competency domains of administering and monitoring therapeutic interventions and regimens include: Starting} and maintaining intravenous therapy with minimal risks and complications, administering medications accurately and safely: Monitoring untoward effects, reactions, therapeutic responses, toxicity, incompatibilities and creating a wound management strategy that fosters healing, comfort and appropriate drainage.

Domains of effective management of rapidly changing situation consist of skilled performance in extreme life-threatening emergencies: Rapid grasp of a problem, contingency management, rapid matching of demands and resources in emergency situations and identifying and managing patient crisis until physician assistance is available. The domains of the teaching-coaching function cover timing: Capturing a patient's readiness to learn, assisting patients in integrating the implications of illness and recovery into their lifestyles, eliciting and understanding the patient's interpretation of his or her illness, providing an interpretation of the patient's condition and giving a rationale for procedures and coaching function: Making culturally avoided aspects of an illness approachable and understandable.

The domains of monitoring and ensuring the quality of healthcare practices include providing a back-up system to ensure safe medical and nursing care, assessing what can be safely omitted from or added to medical orders, recognition of a generic recurring event or problem that requires a policy change and seeking appropriate and timely responses from physicians.

The domains of organizational and work-role competencies consist of coordinating, prioritizing and meeting multiple patient needs and requests, building and maintaining a therapeutic team to provide optimum therapy, providing emotional and situational support to nursing staff, competencies developed to cope with staff and organizational resistance to change, showing acceptance of staff persons to resist system change, using formal research findings to initiate and facilitate system change and using mandated change to facilitate other changes and making the bureaucracy respond to the patient's and family's needs.

The consulting role domains consist of providing patient care consultation to the nursing staff through direct patient intervention and follow-up, interpreting the role of nursing in specific, clinical patient care situations to nursing and other professional staff and providing patient advocacy by sensitizing staff to the dilemmas faced by patients and families seeking healthcare. 


\begin{tabular}{|c|c|c|c|c|c|c|}
\hline Assessment methods & $\begin{array}{c}\text { Job } \\
\text { sample }\end{array}$ & $\begin{array}{c}\text { Job } \\
\text { simulation }\end{array}$ & $\begin{array}{c}\text { Anatomic } \\
\text { model }\end{array}$ & $\begin{array}{c}\text { Clinical } \\
\text { simulation }\end{array}$ & $\begin{array}{l}\text { Written test } \\
\text { performance }\end{array}$ & Appraisal \\
\hline \multicolumn{7}{|l|}{ Advantages } \\
\hline Approximates real situation & $x$ & $x$ & & $x$ & & \\
\hline Assess multiple competencies & $x$ & $x$ & $x$ & $x$ & $x$ & $x$ \\
\hline Patient can report on care & $x$ & $x$ & & & & \\
\hline Replicable & & $x$ & $x$ & $x$ & $x$ & $x$ \\
\hline Evaluates full competencies & $x$ & $x$ & & & & $x$ \\
\hline \multicolumn{7}{|l|}{ Disadvantages } \\
\hline Must wait for situation & $x$ & & & & & \\
\hline Requires extensive resources & & $x$ & & $x$ & $\mathrm{x}$ & \\
\hline Requires trained assessors & $x$ & $x$ & $x$ & & & \\
\hline Potential bias & & & & & & $x$ \\
\hline
\end{tabular}

X: 'Exist"

Question 3: What assessment methods are mostly prefered by students to assess their clinical competence? What are advantages and disadvantages of each assessment method?: Table 2 describes the resume of participants' answer on prefered assessment methods and their advantages and disadvantages.

Table 3 above summarizes assessment methods that were used by nursing education institution to measure clinical competence. There were 6 methods commonly used each of which has its own advantages and disadvantages. In deciding which assessment method will be used, assessors need to consider the three points: (1) What assessment method is available? (2) How can scores be derived based on the method? and (3) Who should observe/evaluate the competence?

Designing training module of clinical competence: In this phase of research, research team used a developmental research method which is very suitable with the study of instructional design and development. The process followed the procedures as presented in the Fig. 1 below.

The training module was designed to enhance nursing students' clinical interviewing, therapy and decision making skills. To reach up the maximum competency standards, students must perform and follow the instructions. Each module consists of a list of readings, a description of the objectives, an explanation of the exercise and evaluation criteria. In all modules students will act as a therapist and practice the skills that are delineated in the readings. In some of the modules, a fellow student will become patients, in others, a clinic graduate assistant (GA) will become patient and in one, lecturers will be their patients. Because each module is different, students must carefully read the instructions for each. Broadly, training draws upon a social learning theory perspective but also incorporates cognitive behavioral and Psychodynamic concepts ${ }^{15}$. Teaching and supervision of clinical skill development is accomplished using a variety of methods and techniques. These include:

- Brief writing tasks of observations of self and peers

- Review of digital recordings

- Simulated case scenarios

- Skill demonstration and modeling

- Role playing

The example of the developed module of nursing clinical competence is displayed in the followings: Module 1: Basic clinical skills.

Learning Outcomes:

- Utilises the appropriate knowledge, skills and attitudes to perform assessment of women and men by means of clinical history taking and physical examination

- Manages problems in a structured and flexible way

- Communicates effectively with women and men from diverse ethnic and social-behavioural groups in a variety of clinical situations and involving other professional groups where appropriate

- Manages time effectively

History taking.

\section{DISCUSSION}

This developmental study identified domains of nursing care and competency, how are competencies acquired, factors affecting nursing performance, competency assessment methods and social factors affecting competency. The results 


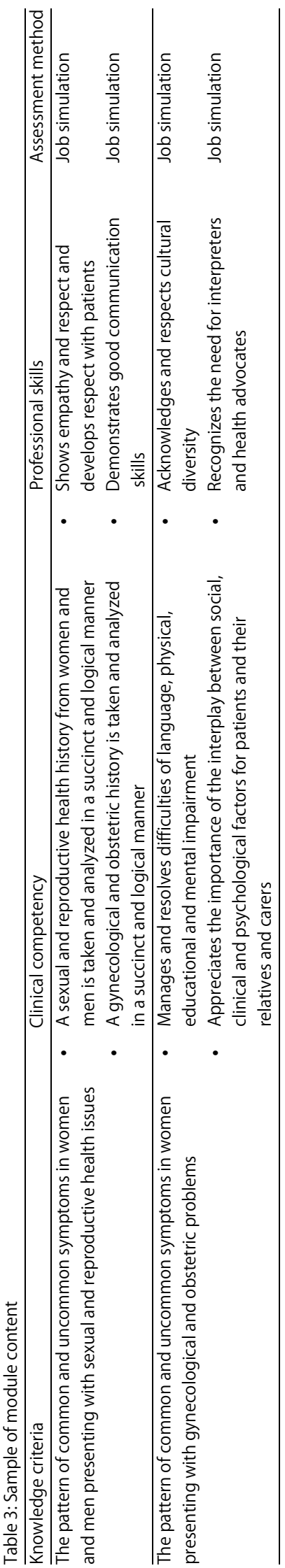

indicated that the training module can increase the overall nursing clinical competency skills and confidence of senior nursing students. Outcomes of the study demonstrated that the module has met the standards of practice which incorporates the six steps of nursing practice by Indonesian Nursing Association (assessment, diagnosis, outcomes identification, planning, implementation and evaluation) ${ }^{16}$ in the definition of the nursing process.

Findings from the previous studies suggest that nursing clinical competency can be improved in various methods and models. Levett-Jones et al. ${ }^{9}$ stated that a quality clinical assessment of nurses' competence requires nursing students' exposure to complex challenges undertaken in authentic clinical contexts trained by assessors who have a strong educational and clinical background. On their view, the most appropriate tool to measure nurses' clinical competence is "the Structured Observation and Assessment of Practice (SOAP), a full day holistic practice driven clinical competence assessment approach that motivates nursing students' learning, promotes critical reflection and guidelines readiness for professional practice.

Further Kim et al. ${ }^{17}$ proposed a model of clinical preceptorship to improve nursing clinical competency. This model provides an essential aspect of nursing education for senior nursing students. The model identified perceptions of senior nursing students about their clinical preceptorship experiences, evaluated their perceived levels of competency and confidence in providing nursing care and examined their perceived confidence level in relation to the perceived competency level of nursing skills to produce a high quality patient care through a continuous training.

The research findings are consistent with current study in that clinical competency trainings in nursing are central to high-quality patient care. It follows that assessing clinical competency is an essential component of professional development and quality improvement efforts that must be performed by nursing education institutions. Therefore, designing a module for improving and measuring nurse clinical competency is a challenging task for the module can support the validity and objectivity of measurements commonly used for various competency assessments.

The result of interview on nursing students reported that nursing students were competent in performing each skill of the nursing process written in the training module by the end of their trainings. Of the nursing process steps, assessment, planning, implementation and evaluation, students were most competent in performing skills related to assessment. The significant differences from initial and final survey responses indicated that the nursing training module was effective in 
improving students' clinical competence as well as their confidence demonstrating each step of the nursing process cycle.

\section{CONCLUSION}

The nursing training module which is based on needs analysis provides the nursing students with an experience as close to an actual work situation. It helps students with the opportunity to gain nursing knowledge, skills and attitudes necessary for performing the nursing processes: Assessment, diagnosing, planning, implementation and evaluation. Results of the study showed that the nursing competency skills improved over time. Outcomes of the study also showed that the improvement of nursing students' clinical competency contribute to their self confidence in carrying out tasks assigned to them. This research is expected to contribute to give new idea and right view to nursing education institutions especially in Indonesia to enable them to design training module for their nursing students to improve their clinical competence based on needs analysis result.

\section{SIGNIFICANT STATEMENT}

The results of this study have provided a clear description of the nurse's competence requirements in the job, the need for highly competent nurses, various assessment of nursing clinical competencies, needs analysis of clinical competencies and design of training modules. The results of this study are very useful for nursing education institutions to design a training module based on careful needs analysis that is very relevant to the needs of clinical competencies required by health care providers. The study is expected to contribute not only to the addition of literature on nursing competence but can directly help nursing graduates improve the ability to perform tasks related to nursing tasks.

\section{ACKNOWLEDGMENT}

The research team would like to thank Directorate of Research and Community Service, Ministry of Research and Higher Education of Republic of Indonesia for financial support for this research project (Grant No. 039/KL1/LT. 1/2017) under the scheme of Penelitian Terapan (Applied Research).

\section{REFERENCES}

1. Levett-Jones, T., J. Gersbach, C. Arthur and J. Roche, 2011. Implementing a clinical competency assessment model that promotes critical reflection and ensures nursing graduate's readiness for professional practice. Nurse Educ. Pract., 11: 64-69.

2. Watson, R., A. Stimpson, A. Topping and D. Porock, 2002. Clinical competence assessment in nursing: A systematic review of the literature. J. Adv. Nurs., 39: 421-431.

3. MoF., 2013. Tentang registrasi tenaga kesehatan. Permenkes nomor 1796. Minister of Health, Republic of Indonesia.

4. Miller, G.E., 1990. The assessment of clinical skills/competence /performance. Acad. Med., 65: S63-S67.

5. PPNI., 2013. Standar Kompetensi Perawat Indonesia. Kepmendikbud No. 045/U/2013, Persatuan Perawat Nasional Indonesia, Jakarta, pp: 121-125.

6. Gibson, F. and L. Soanes, 2000. The development of clinical competencies for use on a paediatric oncology nursing course using a nominal group technique. J. Clin. Nurs., 9: 459-469.

7. Gonczi, A., 1994. Competency based assessment in the professions in Australia. Assess. Educ.: Principles Policy Pract., 1: 27-44.

8. Norman, L. R. Watson, I. Calman, S. Redfern and T. Murrels, 2000. Evaluation of the validity and reliability of methods to assess the competence to practice of pre-registration nursing and midwifery student in Scotland. National Board of Nursing, Midwifery and Health Visiting for Scotland, Edinburg.

9. Levett-Jones, T., J. Gersbach, C. Arthur and J. Roche, 2011. Implementing a clinical competency assessment model that promotes critical reflection and ensures nursing graduate's readiness for professional practice. Nurse Educ. Pract., 11: 64-69.

10. Lee, S. and E.K. Kim, 2017. The effects of Korean medical service quality and satisfaction on revisit intention of the United Arab Emirates government sponsored patients. Asian Nurs. Res., 11: 142-149.

11. Sulastri, L. and N. Marini, 2016. Evaluasi Uji Kompetensi Klinis Perawat Indonesia. Andi, Yogyakarta, pp: 41-43. 41-43.

12. Levett-Jones, T.L., 2007. Facilitating reflective practice and self-assessment of competence through the use of narratives. Nurse Educ. Pract., 7: 112-119.

13. ILO., 2014. National Nursing: Core Competency Standards: Training Modules. ILO Press, Makati, ISBN: 9789221287360, Pages: 400 . 
14. McKillip, J., 1987. Need Analysis: Tool for Human Service and Education. Sage Publications, Thousand Oaks, CA., ISBN: 9780803926479, pp: 11-12.

15. Cormier, S., P.S. Nurius and C.J. Osborne, 2003. Interviewing and Change Strategies for Helpers: Fundamental Skills and Cognitive Behavioral Interventions. 5th Edn., Brooks/Cole, Monterey, CA.
16. PPNI., 2013. Standard Kompetensi Perawat Indonesia. Graha Ilmu Bandung, Indonesia.

17. Kim, K.K., A.Y. Lee, L. Eudey and M.W. Dea, 2014. Improving clinical competence and confidence of senior nursing students through clinical preceptorship. Int. J. Nurs., 1: 183-209. 